\title{
Não-lugares como interfaces urbanas
}

\author{
Non-places as urban interfaces
}

Stéphanie Maia Freire de Andrade, Tiago Barros Pontes e Silva

não-lugares, cidade, experiência urbana, intervenção urbana.

O presente estudo descreve uma trajetória iniciada por uma inquietação sobre a relação das pessoas com os espaços da cidade e como isso influencia na experiência urbana. A pesquisa aborda aspectos que relacionam o design com a escala humana da cidade e o modo como as pessoas enxergam o espaço urbano. Se desenrola também em um processo exploratório de possibilidades e questionamentos sobre não-lugares e sua interação com o espaço urbano. A proposta de intervenção urbana visa repensar as relações e como intervir em não-lugares, a fim de direcionar quem por ali passa a explorar e ocupar os arredores como reflexão de como tornar melhor a vivência na cidade. O resultado se materializa em uma interferência no metrô de Brasília, que tem como objetivo provocar um novo olhar e a curiosidade dos transeuntes aos seus arredores. No entanto, entendemos que o resultado não finaliza a discussão, mas acrescenta novas questões sobre como se utilizar o pensamento de design em reflexões sobre a escala humana da cidade.

non-places, city, urban experience, urban intervention.

This study describes a route initiated by a concern about the relationship of people with the spaces of the city and how it influences the urban experience. The research addresses aspects that relate design to the human scale of the city and the way people see the urban space. It also takes place in an exploratory process of possibilities and questions about non-places and their interaction with urban space. The fulfilled urban intervention aims to rethink relations and how to intervene in non-places, in order to direct those who start to explore and occupy the surroundings as a reflection of how to make a better living in the city. The results are an interference in the Brasilia subway, which aims to provoke a new look and the curiosity of passersby to their surroundings. However, we understand that this result does not end the discussion but adds new questions on how to use design thinking in reflections on the human scale of the city.

\section{Introdução}

Em movimento constante, as mudanças em nossa volta se tornam mais frequentes e somos inseridos em contextos que outrora eram desconhecidos ou distantes. A contemporaneidade tem consigo a tão discutida globalização que, em um dos seus efeitos, ocasionou o maior contato de indivíduos, cidades e países com outros cujas culturas e vivências são frequentemente destoantes. Essa aproximação pode causar também um maior contato e uma ampla absorção no âmbito cultural, como, por exemplo, no ambiente urbano. 
Da perspectiva do design - na abrangência do termo -, cabe entender a relação das pessoas entre si e com o espaço (lugar e arquitetura), além de perceber que tais relações se tornam ainda mais complexas e até desgastantes em contextos urbanos atuais devido aos movimentos de maiores contatos culturais e de globalização, o que abre espaço para discussões de como se pode atuar nas experiências urbanas dos indivíduos.

Em contrapartida, como uma reação a certo nível de homogeneização social e de identidade das cidades, busca-se a individualização e reafirmação de características próprias das cidades como forma de diferenciação e autoafirmação. Os não-lugares, como espaços de circulação, sem identidade e não relacional, são espaços de riscos nos quesitos de uniformidade e generalização do espaço urbano, tornando as cidades cada vez mais sem diferenciação e características próprias (Augé, 1994). Assim, as cidades e países tornam-se paulatinamente pequenos mundos repletos de não-lugares, onde os espaços não se expressam como identidade da cidade e não acolhem os que ali moram ou que estão de passagem.

Embora não seja a colocação dos não-lugares reafirmar a característica identitária da cidade e da apreensão de nós mesmos, não se deve esperar também que tal trabalho seja suprido somente pelos lugares no qual nos relacionamos e a qual sentimos que pertencemos.

Propomos, então, discutir a relação do indivíduo com o espaço a partir de interfaces informacionais, a fim de propor os não-lugares como espaços não mais de uniformização, mas que podem contribuir na imagem da cidade para cada indivíduo e na sensação de percepção do indivíduo como parte dela, beneficiando sua experiência no ambiente urbano.

\section{Revisão teórica}

Baseada também em inquietações e observações, a revisão teórica é adotada como ponto inicial para o desenvolvimento do projeto. Entender a relação de cada um com a cidade, sua identidade e imagem, assim como as interações e experiências no ambiente urbano foram alguns dos pontos que conduziram a pesquisa do projeto.

\section{Os não-lugares no espaço urbano}

As mudanças resultantes do processo de globalização têm relação direta com as novas formas de nos relacionarmos com os outros e com o espaço. Dessa forma, entender o espaço é também ter noção dos novos contextos e relações das cidades com os indivíduos.

Tendo como ponto de partida a compreensão do espaço como a união da configuração natural e das modificações impostas pela vida humana com as relações sociais ali desenvolvidas, de acordo com Milton Santos (2002), podemos começar a compreender também o que compõe esse espaço.

Inseridos no espaço, encontramos dois contextos que são antônimos em sua definição. De um lado, o lugar como um espaço relacional, cheio de significados e dimensões simbólicas para o indivíduo, identitário e até mesmo histórico. O lugar, nostálgico ou rotineiro, acrescenta 
ao espaço a associação da relação entre indivíduos e o preenche de sentido. O não-lugar, por outro lado, nem relacional nem identitário, tem, resumidamente, como função facilitar a circulação (transporte, trânsito, comércio). São "lugares" de passagem. O não-lugar é apático e de pouco ou quase nenhum significado para o indivíduo.

Embora apáticos, os não-lugares são necessários em nosso cotidiano urbano por permitir uma grande circulação de pessoas e informações. O que desperta interesse neles é seu objetivo quase puramente funcional e não na relação que temos com eles ou que eles têm com o restante da cidade.

O não-lugar no espaço urbano, embora inevitável, pode ainda sofrer alterações de características, passando a ser lugar de acordo com a interação que o indivíduo vem a ter. Dessa forma, como faz parte do ambiente urbano, o não-lugar se torna também espaço de relevância no cotidiano daqueles que ali estão e precisam estar inseridos, embora quase completamente desprovido de significados. Se partirmos da ausência de relação do indivíduo com o espaço, a tão somente intervenção de identidade dentro do não-lugar o tornaria em lugar para o indivíduo em questão? Essa mudança poderia também mudar o significado para aquele que tinha aquele espaço como lugar? As respostas para essas questões podem também ser diferentes para cada ponto de vista.

\section{Sobre o ir e vir}

A globalização como um dos processos de integração internacional econômica, política, cultural e social é também um dos facilitadores do ir e vir dos indivíduos e das informações. A redução de distâncias físicas e informacionais por meio do desenvolvimento dos meios de transporte e da internet contribuem também para uma aproximação e convergência no âmbito cultural e comunicacional.

Nosso ir e vir passa a não ser somente dentro da cidade, mas também entre cidades, países e continentes. Dessa forma, esse movimento como ponto de convergência cultural, se torna também um dos pontos para a uniformidade dos espaços urbanos por aproximar e, de certa forma, unificar as vivências nas cidades. E essa aproximação torna também nossa interação com os espaços progressivamente generalizada.

É possível, então, apontar que é o próprio sujeito, a partir de suas experiências e percepções como usuário da cidade, que constrói, ressignifica e transforma o espaço urbano. $\mathrm{O}$ agente transformador é a população que ali reside e, portanto, designa-se à cidade um formato baseado em necessidades, normas, processos de ocupação, manifestações culturais e demais ferramentas de interação política ali estabelecidas (Bonsiepe, 1997).

Nesse ponto, o cidadão passa a ser usuário ativo das cidades a partir de seus deslocamentos e relações com os espaços, gerando elementos convencionados socialmente, gerando vínculo do sujeito com a localidade em si, e com isso um senso de pertencimento com o espaço, dando origem a uma identidade espacial. 


\section{Enxergar a cidade}

Além da configuração arquitetônica com personalidade vestuária da cidade, a sua imagem diz também respeito sobre a percepção individual e fragmentada do ambiente, baseada não somente no senso comum, mas também e, principalmente, nas vivências, experiências e interações particulares de cada indivíduo com a estrutura da cidade.

A rotina, o roteiro, o espaço por onde passa, mora, convive, as ruas, arquitetura e construções é reunido, digerido e traduzido por cada um em um imaginário diferente, transformando uma mesma cidade em múltiplas. Esse imaginário pode, até certo ponto, sofrer influência e ser bastante reproduzido a ponto de se tornar comum para uma maioria de pessoas, podendo transformar essa imagem coletiva em um novo símbolo.

Ainda, cada indivíduo compreende e vivencia esses espaços de uma forma única e "cada uma das formas de representar uma cidade contribui para as sensações que seus habitantes têm dela" (Santos, 2017, p. 47). A imagem construída é o resultado do conjunto de significados atribuídos, muitas vezes de forma inconsciente, pelo observador por meio da sua relação com a cidade. Esse retrato traçado além de contribuir para a criação de uma identidade do seu entorno, contribui com seu reconhecimento e localização na cidade. Sobre esse ponto, Kevin Lynch (1997) propõe que a necessidade de reconhecer e padronizar nosso ambiente é tão crucial e tem raízes tão profundamente arraigadas no passado, que essa imagem é também de enorme importância prática e emocional para o indivíduo.

Por um lado, precisamos de um ambiente com contraste e características individuais marcantes. Por outro, precisamos também da continuidade e padrão em sua forma que seja visualmente organizado e de fácil identificação. Para além da cidade imagética e material, Silva (2006) demonstra uma outra camada para o entendimento do urbano: a cidade imaginada.

Cada indivíduo tem a capacidade de gerar imagens, criar histórias e criar conexões que nunca sequer existiram, apenas baseadas na sua compreensão e vivência.

Assim, o imaginário urbano afeta o significado simbólico e concreto da cidade para aquela pessoa. São as lembranças, experiências, símbolos, ações que transformam compreensão do espaço que se vive e que desencadeia os imaginários urbanos de cada um. E, assim, cada indivíduo se faz capaz de preencher aquele ambiente de significado a partir de suas relações.

\section{Interação na Cidade}

Compreendendo as cidades e seus espaços como pontos de interação com seus habitantes, frequentadores, visitantes e ocupantes, é necessário também entender e se utilizar dessa interação como objeto de estudo de design para os espaços urbanos.

De acordo com Dan Saffer (2010), onde houver qualquer tipo de comportamento ou estudos de como produtos funcionam, devem estar envolvidos designers de interação. Como a maioria das áreas do design, ele também se preocupa com a forma do produto. Porém, a área da interação de design se preocupa principalmente com uma disciplina que o design tradicional, segundo Cooper et al. (2014), não costuma se preocupar: o design do comportamento. Não se trata, então, em pensar na configuração formal do produto e como isso afetará a experiência e 
interação com os usuários, mas pensar a interação final e a partir disso definir o produto ou serviço a ser desenvolvido.

Trata-se de uma perspectiva que aborda o design a partir de uma compreensão de como e por que as pessoas desejam usar os produtos ou serviços, atuando como defensor dos usuários e seus objetivos, segundo Reimann (2001). A interação pode ser entendida, de uma forma simples, como uma transição entre dois objetos, uma troca de informação entre pessoas, máquinas, artefatos e sistemas, em um infinito de possíveis variáveis. No entanto, Saffer (2010) descreve o design de interação não somente como um solucionador de problemas, mas aborda também como as soluções e produtos com foco na interação transformam o mundo para que seja um lugar melhor para se viver. Neste sentido, a afirmação se relaciona com o modo pelo qual pensamos e ocupamos a cidade.

Os trajetos que percorremos, nossa rotina, os lugares preferidos, o transporte, a arquitetura, história, contatos, sinalização ou a troca de informações, tudo isso diz respeito a interação dos indivíduos com a cidade. Compreender esses indivíduos, seus caminhos e suas interações é também observar o intercâmbio dessas pessoas com a cidade. Se os projetistas modificam o mundo pouco a pouco, designers que repensam a cidade e suas interações têm o potencial de modificar um amplo contexto urbano.

\section{Metodologia}

O delineamento adotado se apoia na abordagem de pesquisa pelo design, na qual os resultados são buscados a partir da prática de projeto, mesclando a produção de conhecimento às intervenções realizadas simultaneamente. Assim, o estudo contou com a flexibilidade procedimental necessária para a manutenção do sentido de investigação ascendente, construindo as principais hipóteses e experimentações em campo para garantir uma maior aderência à realidade local, mas ao mesmo tempo privilegia uma perspectiva poética da sugestão de um novo significado ao espaço.

Portanto, o processo de design é resultado de constante estruturação de etapas, seguindo uma trajetória muitas vezes não linear. As etapas de levantamento bibliográfico e estudo de sistemas similares ocorreu de modo concomitante a uma investigação sensível de construção de um olhar subjetivo da cidade, que ocorreu por meio de um ensaio fotográfico exploratório. Neste processo, a observação global do comportamento das pessoas em locais públicos da cidade fomentou reflexões sobre as possíveis intervenções a serem realizadas. Estes procedimentos foram seguidos de etapas mais sistemáticas de levantamento, como a análise de não-lugares enquanto alternativas para receber as intervenções, analisando-se seus aspectos de viabilidade e suas microestruturas. Ainda, ao longo do processo, foram realizadas fases de ideação e estruturação em variados níveis de abstração, que resultaram na proposta selecionada, materializada em etapas posteriores de definição de fluxos e narrativas, desenvolvimento de uma linguagem visual e a definição de suas interfaces. Após a realização 
das intervenções, novas observações globais participativas com entrevistas não estruturadas foram realizadas com as pessoas que transitavam no local da intervenção.

Enquanto suporte para sua visualização e organização, o percurso foi registrado em um painel de inquietações e ideações do projeto que serviu como forma de registro e apreensão de todo o processo que leva um projeto de design (Figura 1).

Figura 1: Painel de registro do percurso projetual.

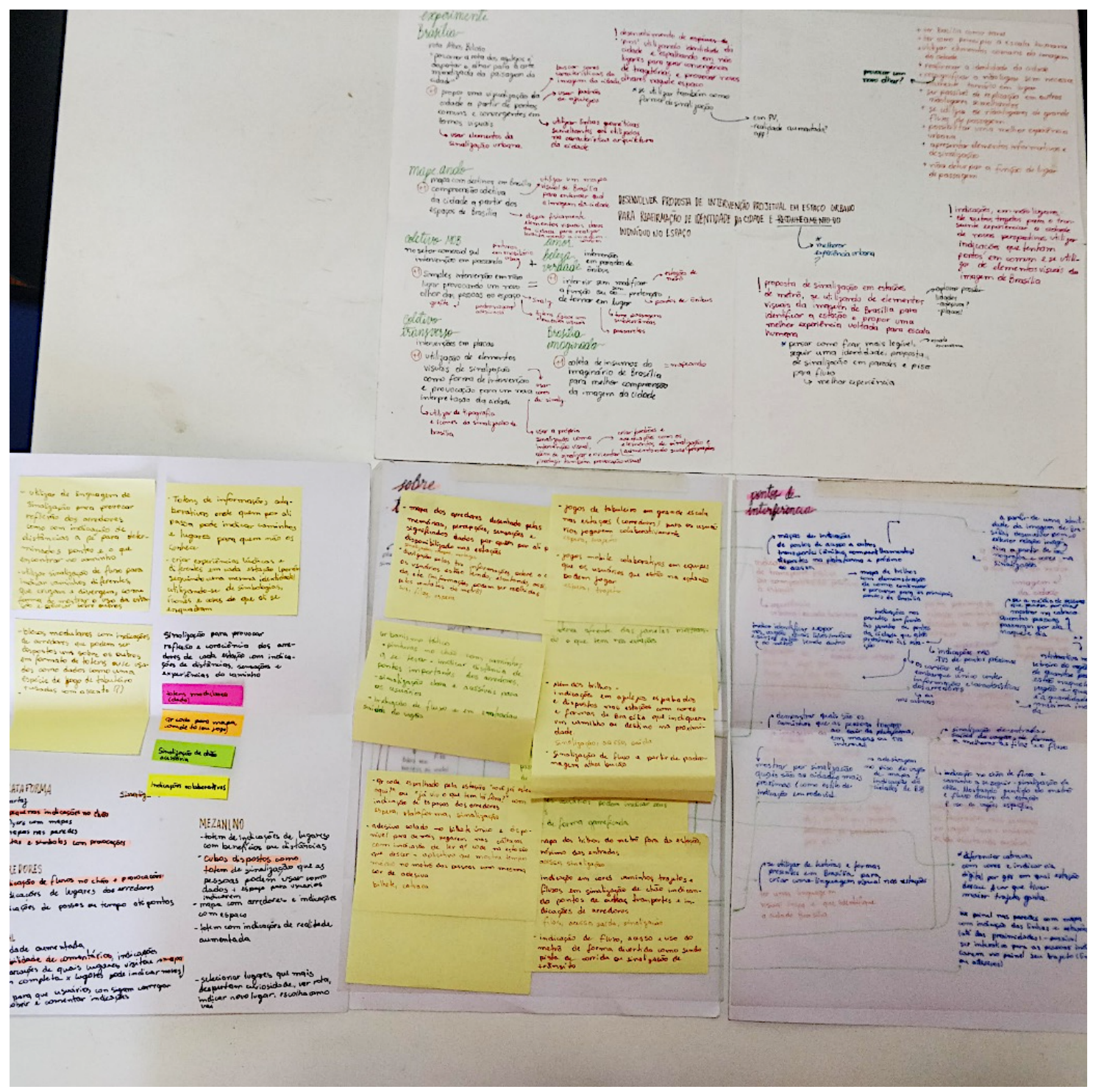

O painel foi gerado e expandido a cada nova etapa do projeto, como um diário de pesquisa, desenvolvendo uma forma de narrativa em camadas, auxiliando o processo decisório, as interpretações, e também as fases de geração de alternativas. Ao final, o painel se torna igualmente uma ferramenta, favorecendo o alinhamento entre insights de projeto, os conceitos investigados e a interpretação das transformações provocadas. 


\section{Definindo por onde passar}

Brasília é uma cidade planejada na escala monumental, de imagens vistas de cima, de longe, de grandes distâncias. No entanto, por mais díspar que seja das demais cidades do país, o que está na escala humana da capital, a nível dos olhos, é o que cada um experimenta e absorve da cidade. Assim, a partir de um ensaio fotográfico inicial (Figura 2), com objetivo de tratar da Brasília que vemos e vivemos, a nível dos olhos, das sensações cotidianas, das cores, das texturas, buscou-se tratar da imagem monumental a partir dos microfragmentos imagéticos que é a tradução da cidade de quem a vive.

Figura 2: Ensaio fotográfico realizado sobre Brasília.
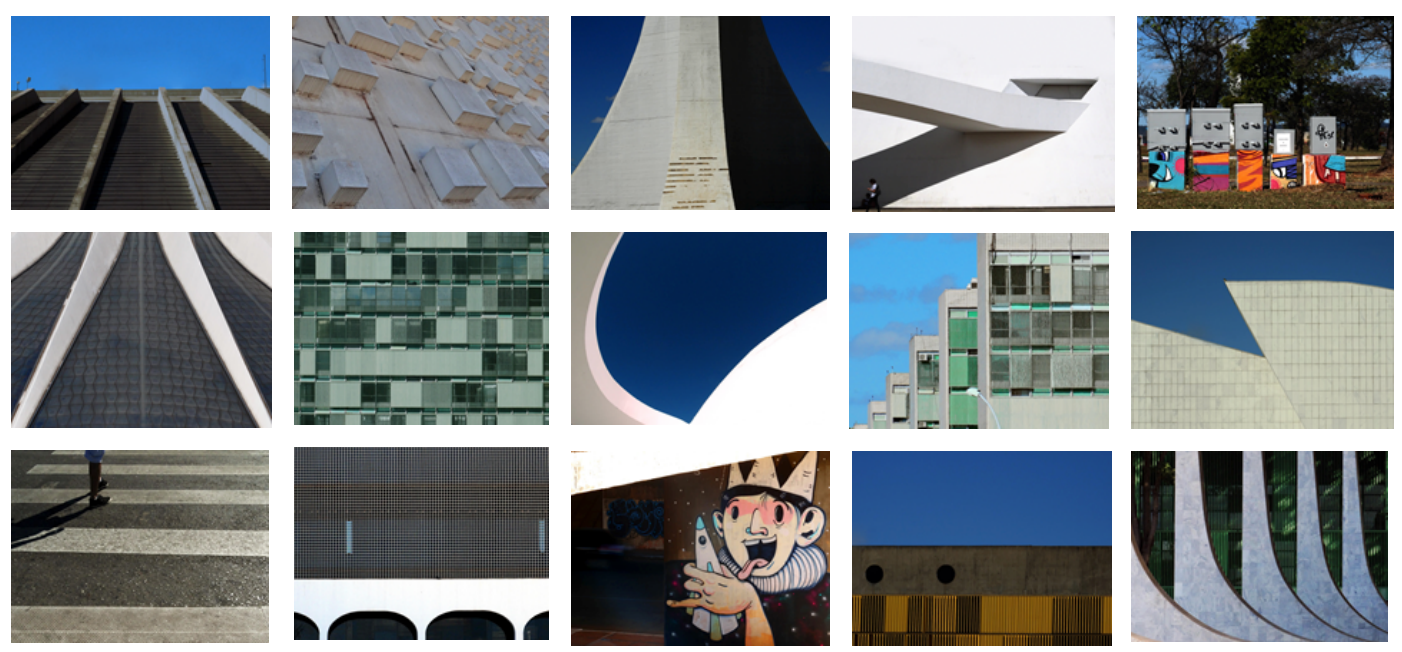

De um ponto de vista, a partir da interface urbanística de Brasília, as fotografias foram registradas como aquilo que se vê por quem está nessa interface. São recortes e percepções de quem circula e interage, mesmo que de forma ínfima, com a cidade. "Interfaces são, em sua maioria, entradas, calçadas, rampas e escadas, estacionamentos improvisados, pequenos arruamentos ou mesmo áreas de parques e jardins.” (Fragomeni et al., 2015, p. 55).

As linhas retas e curvas, as texturas, as cores, o concreto, os azulejos e as padronagens arquitetônicas se mostram como principais protagonistas da imagem imposta pela proposta de Lúcio Costa e do arquiteto Niemeyer. A visualização do conjunto de imagens do ensaio resulta em uma configuração visual da capital. Dessa forma, o estudo inicial propicia uma base para o entendimento e desenvolvimento projetual, buscando referências que condizem com a imagem e identidade de Brasília.

\section{Processos de infiltração}

Isabella Brandalise (2016) propõe uma forma de investigação sobre as navegações e narrativas dos sistemas urbanos. Partindo de um ponto similar da presente exploração, de uma inquietação teórico-prática de especulações de mundos possíveis. Utilizando a cidade como laboratório, como ela mesma descreve, para expor operações como formas de infiltração. Além 
disso, também discorre sobre as possibilidades de abertura, especulação e imaginação como resultado da infiltração.

A proposta de infiltração e a capacidade de imaginação e experimentação de novas formas de viver e interagir com os espaços reivindica a desautomatização das experiências cotidianas. Cada um dos comportamentos e relações dos indivíduos com os sistemas ao seu redor se tornam um possível estudo e atualização do planejamento urbano. "São navegações nos espaços e tempos intersticiais, caminhos insólitos para mundos possíveis. Em outras palavras, são usos, apropriações e imaginários das pessoas que fazem da cidade um sistema vivo e experimental" (ibidem, p. 37).

A infiltração pode ser traduzida como um potencial de transformação que se utiliza das fissuras do sistema. Já que consideramos sempre o contexto, sistemas e serviços para pensar e produzir objetos e artefatos, compreender os espaços dessas variantes se torna uma oportunidade para processos de infiltração.

No diagrama elaborado em seu trabalho, Brandalise traduz a relação $A B$ como um esquema de entendimento entre a ideação e concepção do espaço (B) e com seus usos, apropriações e vivências $(A)$, trazendo aqui as potenciais formas de infiltração. "Não se contenta com formas de participação passiva, agindo em prol de uma contestação da vida cotidiana, mesmo que em uma microescala e sem articulação consciente" (ibidem, p. 65). É, então, uma metodologia que tira vantagem das regras prescritas, criando uma espécie de jogo com o sistema imposto.

A abertura se faz como uma reflexão final sobre os possíveis resultados que a metodologia de infiltração pode causar nas operações e experiências da cidade. Essa relação infiltraçãoabertura entende-se a partir de uma imaginação ativa, na ação de saída para o espaço de desautomatização do sistema. Parte de um indivíduo não mais passivo, que passa a enxergar a cidade com curiosidade e vontade de explorá-la e até ocupá-la.

Nas experimentações da autora, como protótipos iniciais dessa metodologia em menor escala, foram dispostas uma série de seis placas de sinalização no Washington Square Park em Nova lorque. Feitas à mão, as placas se utilizam da mesma linguagem visual da sinalização oficial do parque, porém com informações irreais e até que causam certo estranhamento, como "Você pode estacionar sua espaçonave aqui". A resposta do público foi espontânea e pôde ser avaliada por meio de postagens na rede social do Instagram.

\section{Identificação de brechas}

Para a realização da intervenção urbana, o presente estudo buscou espaços como possíveis lugares de atuação de uma interface não significativa para os transeuntes em forma de uma interface urbana na experiência da cidade. Eles foram analisados a partir de requisitos levantados para possíveis intervenções. Apesar de abrangentes e não definitivos, esses pontos servem como base, em conjunto com os conceitos já levantados, para a análise dos 8 lugares identificados enquanto oportunidades: ponto de ônibus, estação de metrô (embarque e desembarque), estação de metrô (corredores), gramados centrais do eixo monumental, ICC 
(Universidade de Brasília), calçada entre Conjunto Nacional e Conic, rodoviária e setor comercial sul.

Dessa forma, a estação de metrô, entendida como toda sua extensão, tanto como em suas mais diferentes localidades quanto seus diversos espaços internos, foi escolhida como objeto de estudo para o presente estudo. O metrô como meio de transporte urbano, lugar de passagem, pode ser visto como espaço apático e não significativo por algumas pessoas que por ali passam e onde os espaços e informações disponíveis devem ser claras e ergonômicas, com foco em sua escala humana e também de fácil acesso e estudo de observação, torna-se assim um objeto considerado adequado para o projeto.

Como forma de análise de pontos de contatos e intersecção, se entendeu a necessidade de utilizar como base para o levantamento de propostas o estudo de áreas possíveis com que o usuário interage na estrutura da estação. A compreensão desses pontos e todas suas variáveis se fez como um caminho lógico para o reconhecimento da estrutura de onde se busca trabalhar. Cada item listado abre um outro leque de novas estruturas que evidenciam a materialidade de uma interação completa do usuário na estação do metrô, podendo ser compreendidos aqui como espaços intermediários que constroem a narrativa do indivíduo no espaço como um todo. Essa etapa pode ser compreendida como uma expansão de possibilidades e de recursos potenciais a serem utilizados nos próximos passos.

As principais materialidades observadas são divididas em quatro pontos principais: os vagões, plataforma, acesso e corredores. Cada um desses pontos foi destrinchado para outras possíveis micro interações estruturais, narrativas e de informação com os usuários, assim como possíveis ocasiões e ações naquele espaço.

Pensando nos fluxos e narrativas possíveis, essas ramificações buscam abarcar o maior número de possibilidades de estruturas circunscritas em cada um dos quatro pontos e na estação. Também se torna evidente que alguns desses pontos secundários se encontram em mais de um dos quatro pontos principais. Nos corredores, suas ramificações consistem em: cartazes informativos, filas, deslocamento, acúmulo de usuários, possíveis amostras e intervenções, possíveis pontos de serviços, seguranças e placas/sinalização. Essa última ramificação, por exemplo, pode ser encontrada em outros dois pontos de contato.

Após o levantamento de todos os pontos, suas ramificações e convergências, buscou-se compreender os pontos de interferência, como uma listagem de oportunidades de possíveis interações. Esses pontos tratam de contextos gerais baseados nos requisitos abrangentes citados acima para direcionar propostas a serem desenvolvidas posteriormente. Um desses pontos, como exemplo, é uma proposta de contribuir que os usuários se sintam movidos a conhecer mais da cidade pela compreensão do trajeto de outros usuários, como por onde passam e quais lugares indicam.

Pode-se identificar, ainda, que os pontos de interferência listados podem ser divididos em alguns focos como a experiência urbana, a escala humana, imagem da cidade e no deslocamento. Esses pontos de interferência traduzem em um primeiro direcionamento para a 
criação de requisitos mais específicos e, assim, para as etapas de geração de alternativas. Esses requisitos são:

- Utilizar não-lugares como direcionamento para ocupação dos espaços da cidade;

- Utilizar de elementos de sinalização como intervenção;

- Ser interativo;

- Ser colaborativo;

- Propor novos olhares para a cidade a partir da saída da rotina;

- Ser passível de replicação em outros não-lugares semelhantes.

\section{Através do quadrado}

Para finalmente desenvolver e colocar em prática a proposta, se fez necessário utilizar os requisitos do projeto Cultura no Metrô, que possibilita exposições nas estações do metrô de Brasília, como limites de projeto. Assim, para um primeiro teste, foi desenvolvido um produto mínimo viável (MVP) na estação localizada na quadra 108 Sul do Plano Piloto.

Para essa etapa, foi feita uma pesquisa geral de referências visuais e de suportes de sinalização, traduzidos em um painel de referências de formas, linguagens e elementos estruturais. A partir desse painel, e compreendendo o fluxo de interação construído, foi desenvolvida a proposta de mecanismos materiais como interfaces.

A partir de um estudo de localidades e arredores da estação, foram levantados pontos a serem indicados na proposta, são eles: quadra modelo, primeira quadra de Brasília, cobogós, espelho d'água com carpas, Athos Bulcão e igrejinha, cafés e restaurantes da 208, corredores e passagens arborizadas como alamedas, banca da 108, banca da 308 , copacabanca 208 sul, cine Brasília e Casa D'Italia. Com todos os pontos básicos e formais da proposta já levantados e listados, foram realizadas etapa de ideação de configuração formal e física da proposta de intervenção.

Algumas das restrições colocadas pela organização do metrô foram a impossibilidade de intervir nos vagões e em forma de sinalização de piso. Assim, nos pontos das plataformas e corredores a proposta precisou ser adaptada para uma infiltração no contexto dos usuários, que provocasse curiosidade a partir das frases e cores, mas ainda assim fosse discreta. Para isso, foram desenvolvidos 12 adesivos quadrados $(10 \mathrm{~cm})$ como forma de sinalização próxima aos pontos escolhidos nos arredores da estação 108 Sul (Figura 3). 
Figura 3: Adesivos concebidos para a estratégia de infiltração nos vagões do metrô.

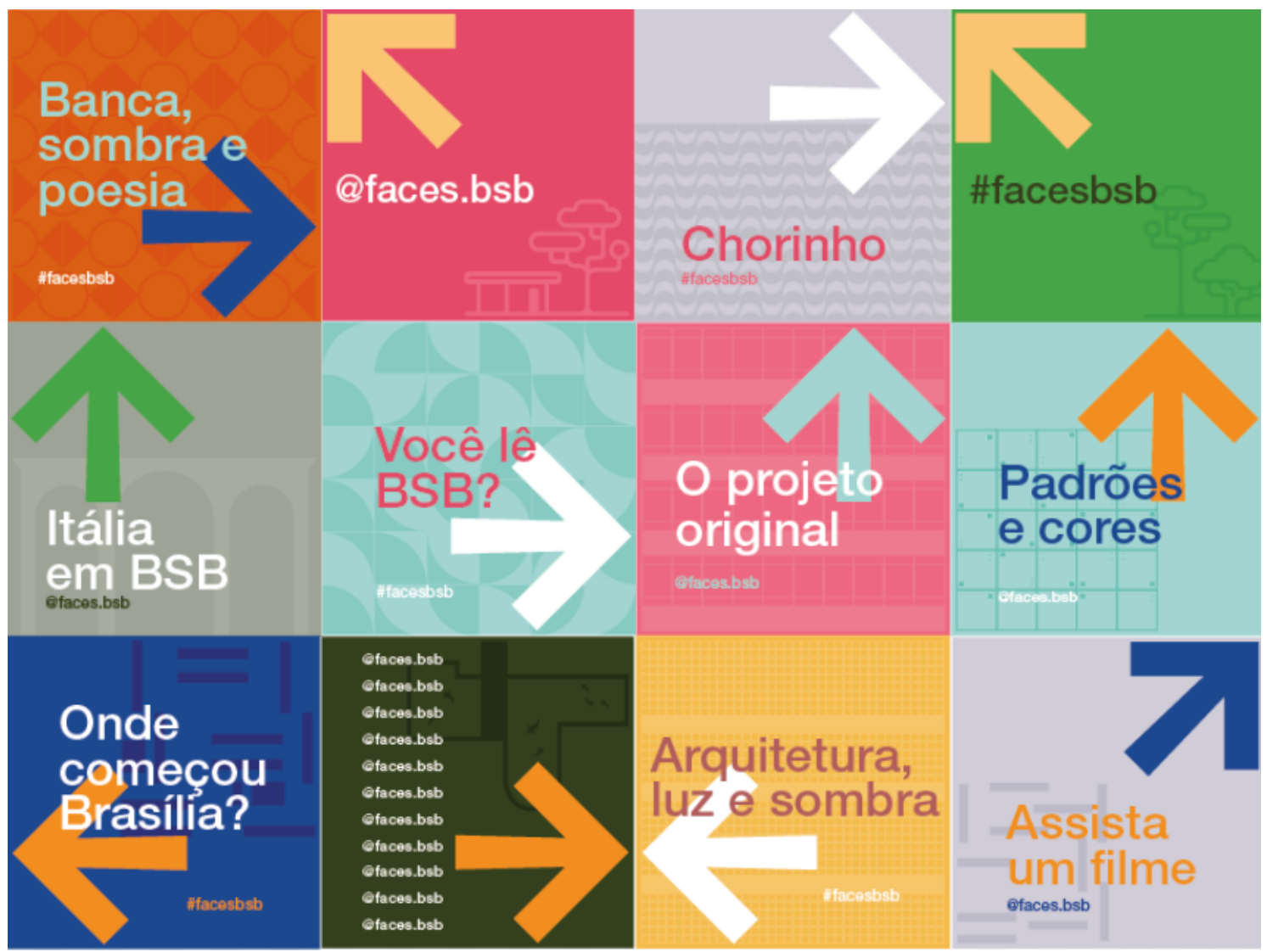

Também foi planejado um totem para ficar disposto na estação (Figura 4). Adaptações foram necessárias por se tratar de um espaço de passagem subterrânea que fica aberto $24 \mathrm{~h}$ por dia. Todos os cubos $(30 \mathrm{~cm})$, com exceção da base, têm quatro de suas faces adesivadas com indicações de lugares dos arredores, propostas de novos caminhos e com algumas faces em branco para que os próprios usuários escrevam indicações de outros lugares.

Figura 4: Render inicial da proposta para o totem.

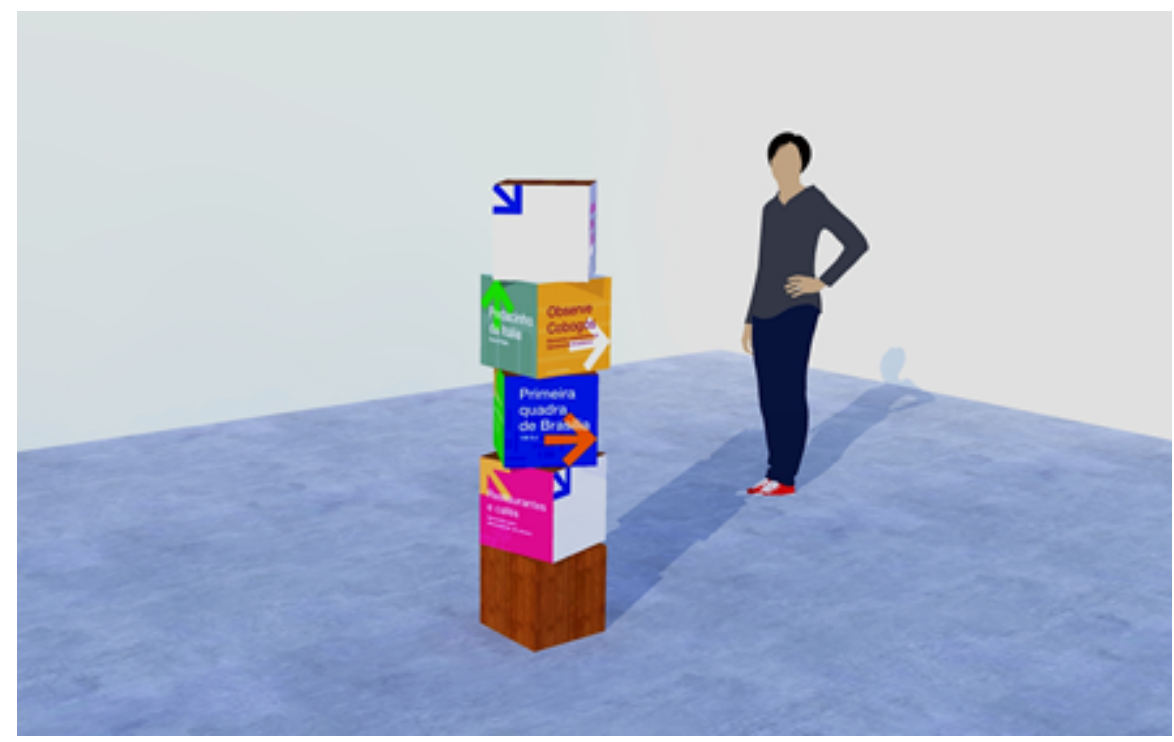


Como extensão da proposta para o universo digital, foi desenvolvida uma conta no aplicativo do Instagram para incentivar as pessoas que tiveram contato com a intervenção física a compartilharem seus pontos de vista, caminhos e lugares em Brasília. Ela também permite que as pessoas que não tiveram contato com o totem, mas chegaram ao projeto pela infiltração nos vagões possam se envolver. O objetivo desta expansão é ainda provocar novos olhares para a cidade e incentivar a ocupação, exploração e compartilhamento de novos lugares. Para isso, foi criada a programação de uma série de postagens para levar o usuário a esses novos caminhos. Além disso, ela contempla um mapa digital com as especificações de todos os lugares indicados no totem disposto na estação 108 Sul.

\section{O Projeto de intervenção Faces}

Como parte do projeto, agora intitulado Faces, o totem interativo desenvolvido (Figura 5) ficou disposto na estação 108 Sul do metrô de Brasília por oito dias corridos, do dia 13 de outubro de 2019 até o dia 20 de outubro. Autorizado conforme inscrição no regulamento do programa Cultura no Metrô, se fez necessária uma visita técnica junto com funcionários do metrô para decidir o local de exposição da proposta. O totem deveria estar disposto sem atrapalhar o fluxo de pessoas, mas ainda que pudesse ser visualizado por quem passa pela estação por todos os acessos (pelo metrô, pela saída 108 Sul e 208 Sul).

Figura 5: Totem exposto na estação 108 Sul em Brasília.

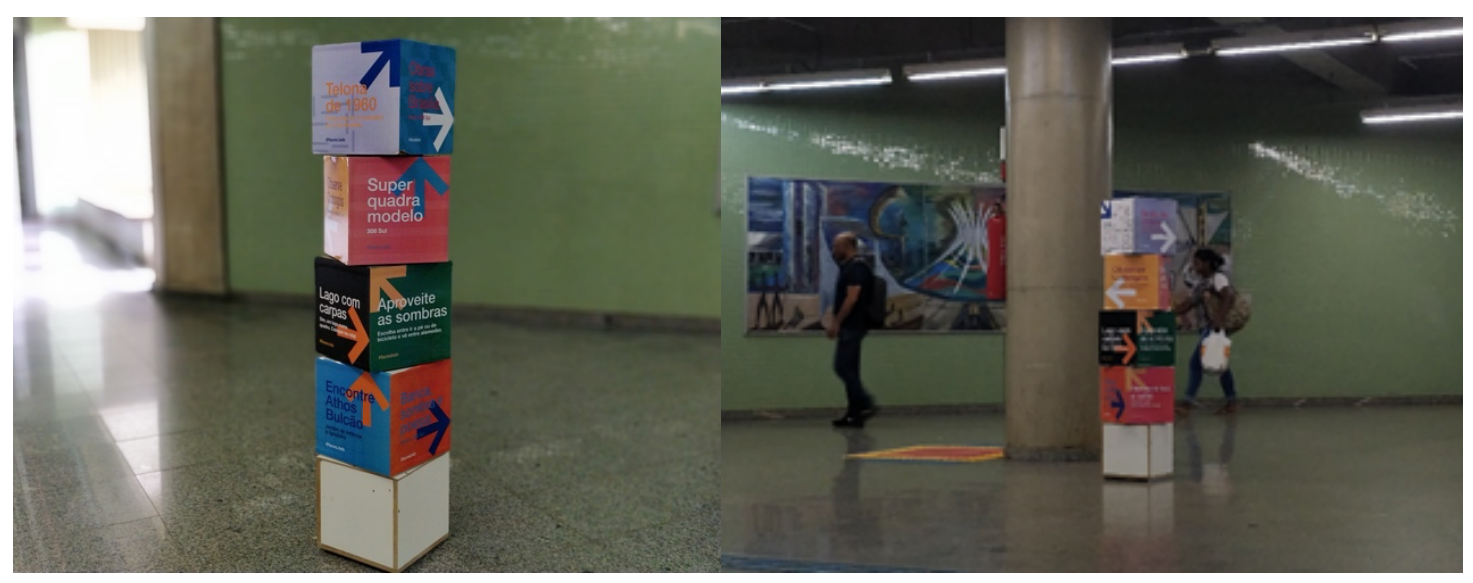

No decorrer dos dias em que ficou exposto na estação, foi observada a interação registrada pelas escritas nas faces do totem com novas indicações de usuários. O conteúdo das interações, como já previsto, passavam desde reais indicações dos lugares dos arredores, como também exposição de perfis de redes sociais de algumas iniciativas privadas e até grafismos de linguagem de pichação (Figura 6). 
Figura 6: Indicações escritas no totem.

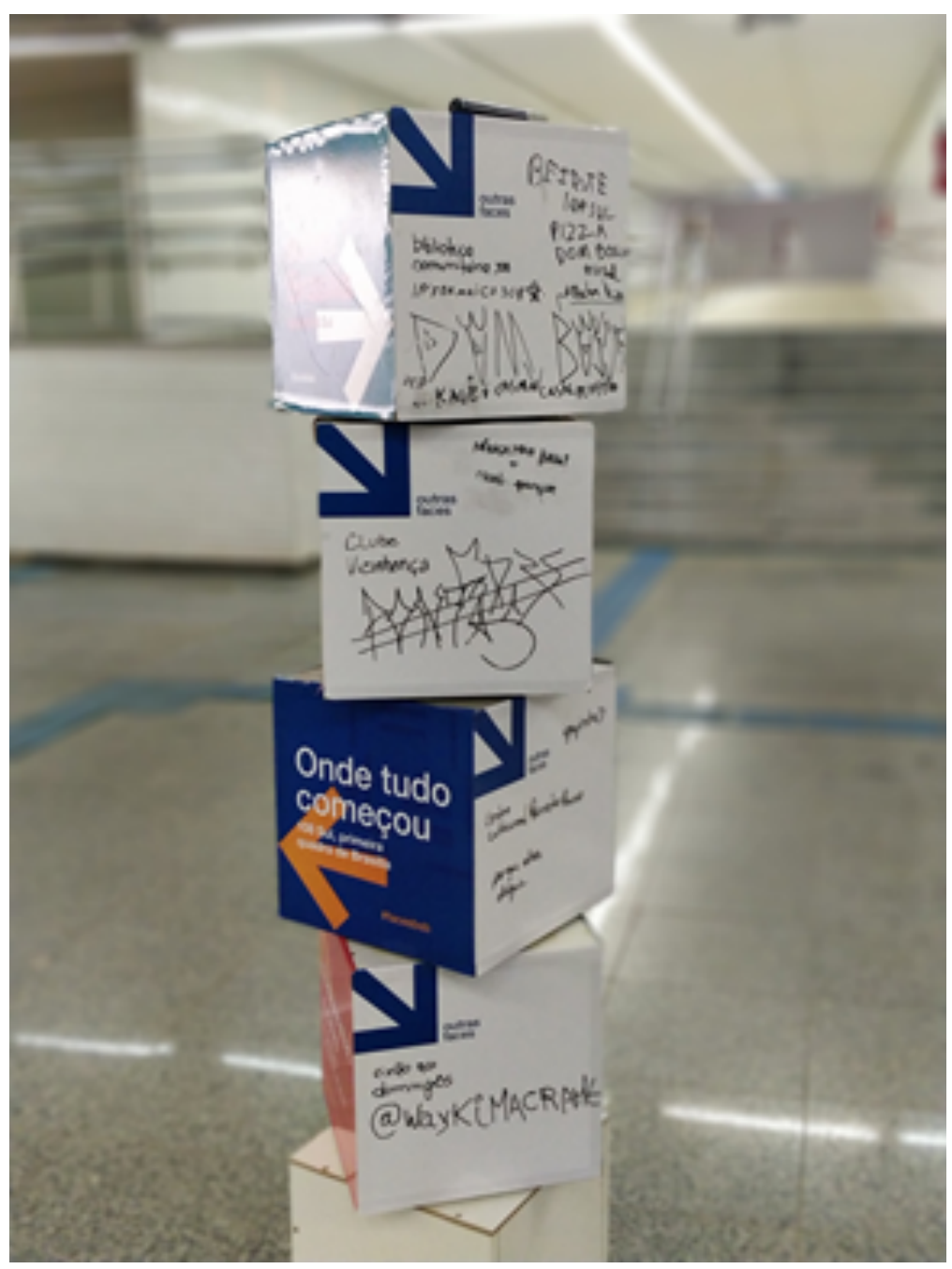

Observando a interação diretamente na estação, ficou evidente que a maioria das pessoas que por ali passava examinava a proposta com certa curiosidade, porém seguia em seu caminho. Uma quantidade menor de pessoas parava para observar e até girar as faces do totem. Uma outra quantidade menor de usuários chegou a intervir no totem escrevendo suas indicações. No entanto, observou-se que, destas pessoas, algumas poucas foram convertidas em interações digitais pelo Instagram (Figura 7). 
Figura 7: Perfil criado para o projeto Faces no Instagram.

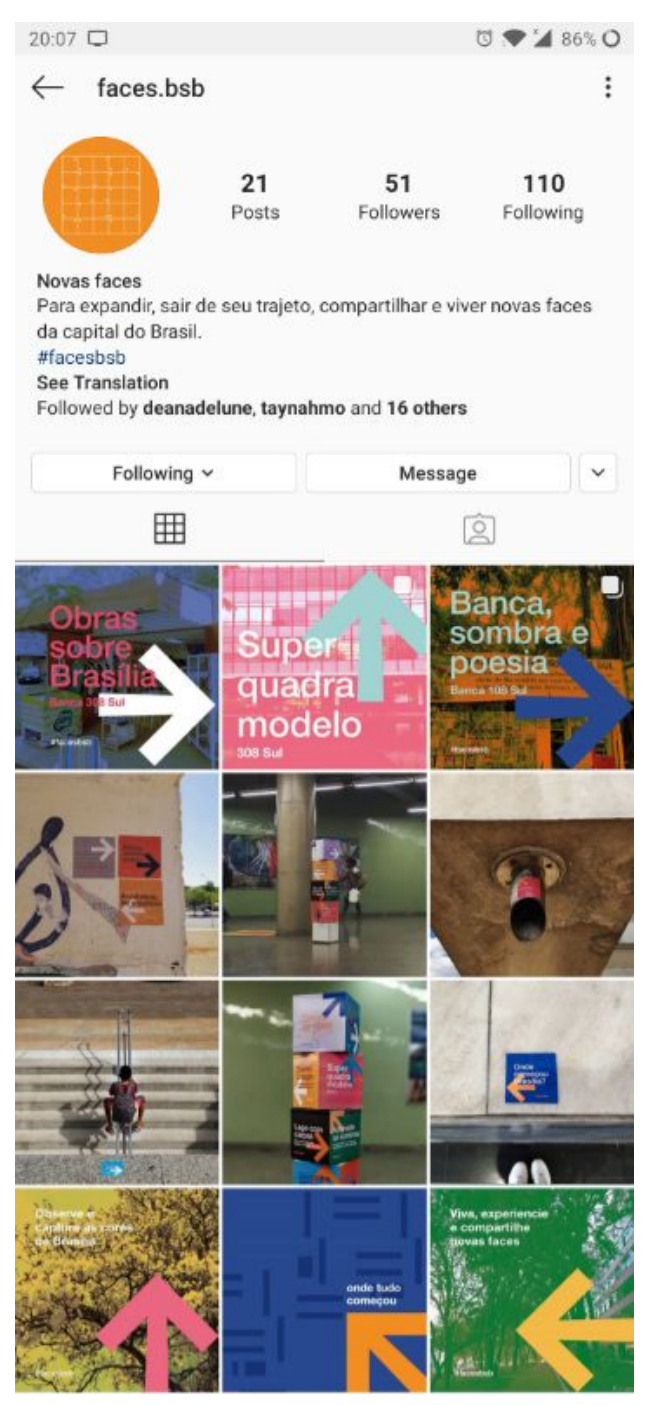

Além do totem, durante esses mesmos dias, e por mais uma semana conseguinte, foi também realizada a proposta de infiltração por meio da colagem de adesivos nos arredores das estações de metrô, em algumas paradas de ônibus e próximo aos lugares indicados (Figura 8). Destas, as dispostas nas estações de metrô foram retiradas mais rapidamente, mas as intervenções nos arredores e próximo aos lugares indicados continuaram por mais dias. 
Figura 8: Exemplos de adesivos infiltrados na paisagem urbana.
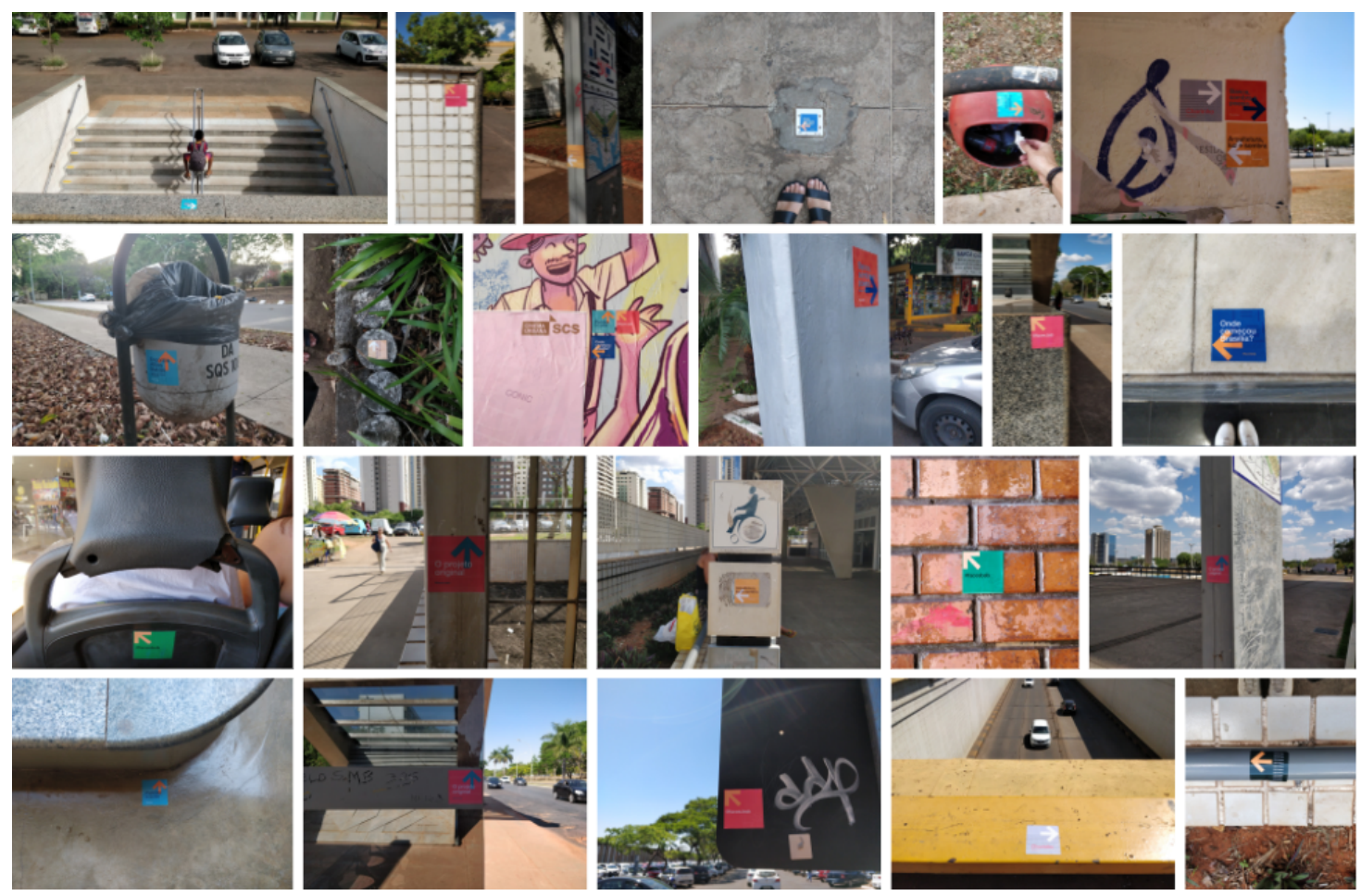

A
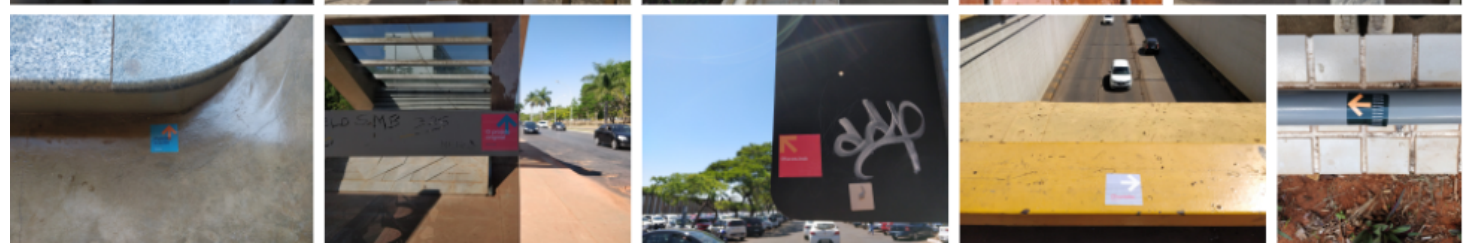

\section{Discussão e Conclusão}

Os não-lugares, como partes muitas vezes indissociáveis do ambiente urbano, podem também ser entendidos como parte importante para um melhor planejamento para a escala humana de uma cidade. Compreendendo a cidade como ambiente de vivências e deslocamentos humanos, pensar a experiência urbana como algo que beneficia todos que ali vivem $e$ transitam, significa pensar também na interação com os espaços da cidade.

O estudo de como as pessoas se utilizam de não-lugares, como o metrô, suas estações e passagens subterrâneas em Brasília, se fez um ponto de partida para um questionamento de como esses espaços podem também ser incorporados num planejamento para uma cidade à altura dos olhos, pensada para na dimensão humana, para quem a experimenta de perto e cotidianamente.

Dessa forma, ter o metrô como não-lugar e, assim, como interface de um possível planejamento para a escala humana da cidade, pode ser também um exercício para repensar como utilizar esses espaços, tornar o ir e vir na cidade uma melhor experiência e direcionar as pessoas que por ali passam para ocupar espaços como forma de reforçar a imagem da cidade. Segundo Augé (1994), o movimento acrescenta à coexistência dos mundos a experiência combinada do lugar antropológico e daquele que não o é mais.

Planejar como os não-lugares podem levar as pessoas a conhecer seus arredores pode se tornar parte da preocupação da experiência urbana e, de acordo com Gehl (2013), “(...) uma preocupação crescente com a dimensão humana no planejamento urbano reflete uma exigência distinta e forte por melhor qualidade de vida urbana", assim como o planejamento 
físico da cidade. O reconhecimento desses lugares reforça a identidade da cidade e também a profundidade e a intensidade potenciais da experiência humana (Lynch, 1997). Ainda segundo Lynch, a circulação e os usos do espaço urbano são funções fundamentais que as formas da cidade podem expressar.

O presente estudo parte de provocações para levantar possibilidades e questionamentos sobre o caminhar, ocupar e construir a relação com a cidade em que se vive. Como um experimento inicial, a proposta visa suprir uma primeira inquietação sobre o conhecimento da cidade e arredores das estações por quem por ali passa diariamente. No entanto, para uma melhor interação e um melhor resultado de indicações, por exemplo, seria necessária uma proposta de experiência completa, que fosse reforçada em vários níveis, como uma gradação de provocações de curiosidade nos vagões, plataformas e em outras áreas da estação.

O deslocamento de cidadãos na cidade e a ocupação dos espaços transforma esses indivíduos em agentes ativos, gerando também um melhor desenvolvimento da imagem coletiva da cidade. Impulsionar esse caminhar e os vínculos com a cidade propicia também um melhor reconhecimento e experiência do ambiente urbano. Nesse sentido, para um melhor resultado, acredita-se que a infiltração pode ser mais incisiva para provocar curiosidades aos interagentes. Assim, também a interação digital pode ser mais efetiva, para que seja mais evidente o processo de abertura da infiltração, sendo capaz de observar o indivíduo como agente ativo e explorador do espaço, saindo da automatização de seu cotidiano.

Apesar da presente inquietação ter partido da cidade de Brasília, com suas características arquitetônicas marcantes, que cria uma imagem da cidade focada na sua escala monumental, tornando sua escala humana muitas vezes precária, as intervenções aqui descritas podem também ser adaptadas e redimensionadas para fomentar provocações em outras cidades.

Discutir o ambiente urbano, a relação das pessoas com os lugares e não-lugares, leva também a compreensão da cidade como um espaço de interações, como interfaces urbanas e também como objeto de estudo de design. $O$ design da informação aliado à escala humana no planejamento dos ambientes pode influenciar ainda mais na qualidade de uso de áreas urbanas e nas suas ocupações cotidianas. Além disso, incluir os não-lugares no estudo como parte importante da vida cotidiana da cidade é também perceber o caminhar como movimento de ocupação e experiência da cidade, fazendo do usuário um agente ativo e observador do ambiente urbano.

O projeto propõe, assim, uma discussão teórica da relação do design com o planejamento e compreensão da cidade a partir do ponto de vista de não-lugares. E essa discussão pode também enriquecer futuras pesquisas e projetos que se apropriem de conceitos, questionamentos e caminhos semelhantes. Por fim, o projeto não tem intenção de encerrar discussões sobre a cidade, sua ocupação e o pensamento projetivo sobre ela, nem concluir em propostas finais para solucionar problemas interação e experiência urbana. Mas sim, abrir mais provocações para incluir o design da informação enquanto espaço de ressignificação do pensamento da cidade. 


\section{Referências}

Augé, M. (1994). Introdução a uma antropologia da supermodernidade. Trad. Maria Lúcia Pereira. Campinas: Papirus.

Bonsiepe, G. (1997). Design: do material ao digital. Florianópolis: FIESC/IEL.

Brandalise, I. V. M. (2016). Infiltração e abertura para cotidianos eventuais.

Cooper, A., Reimann, R., Cronin, D., \& Noessel, C. (2014). About face: the essentials of interaction design. John Wiley \& Sons.

Costa, L. (1991). Relatório do Plano Piloto de Brasília. Brasília: Governo do Distrito Federal.

Costa, L. (1987). Brasília Revisitada. Disponível em:

<http://urbanistasporbrasilia.weebly.com/uploads/9/4/0/4/9404764/brasiliarevisitada.pdf>. Acesso em: 30 de set. 2019.

Fragomeni, A; Fonceca, R; Brandão (2013). Brasília - Não vivemos em cartões postais. Brasília: Editora Gilgamesh.

Gehl, J. (2013). Cidades para pessoas (Vol. 2). São Paulo: Perspectiva.

Cultura no Metrô. Disponível em: <http://www.metro.df.gov.br/?page_id=10961>. Acesso em: 20 de out. de 2019.

Lynch, K. (1997). A imagem da cidade. São Paulo: Martins Fontes.

Reimann, R. (2001). So you want to be an Interaction Designer. Disponível em: <https://www.cooper.com/journal/2008/05/so_you_want_to_be_an_interacti/>. Acessado em: 02 de out. 2019.

Santos, M. (2002). A natureza do espaço: técnica e tempo, razão e emoção (Vol. 1). Edusp.

Santos, F. A. Comunicação Visual e Design como índice da Complexidade Semiótica do Espaço Urbano. Camara, R. J.; Santos, F. A. (orgs.) Urbanidade: Mediações. Brasília: Estereográfica, 2017.

Saffer, D. (2010). Designing for interaction: creating innovative applications and devices. Berkeley: New Riders.

Silva, A. (2006). Imaginários Urbanos. 6a ed. Bogotá: Arango Editores.

\section{Sobre o(a/s) autor(a/es)}

Stéphanie Maia Freire de Andrade, Bacharela, UnB, Brasil <stephanie.mfda@gmail.com>

Tiago Barros Pontes e Silva, PhD, UnB, Brasil <tiagobarros@unb.br> 